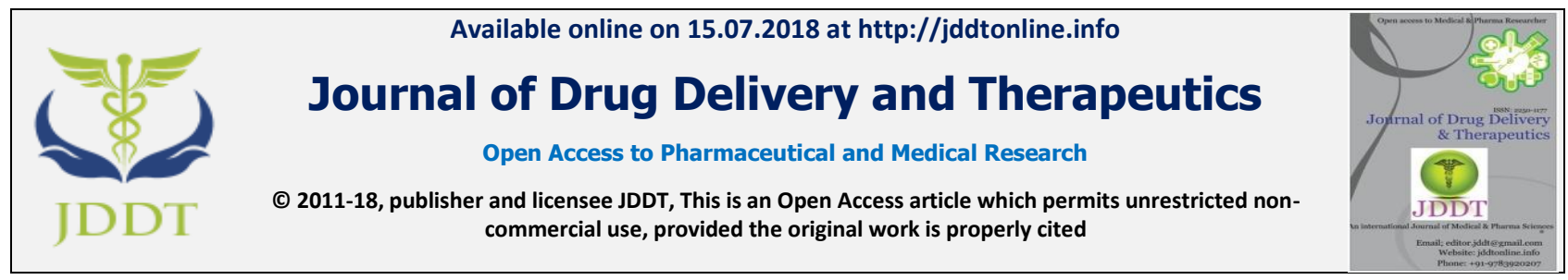

Open Access

Research Article

\title{
NEW SPECTROPHOTOMETRIC DETERMINATION OF ESOMEPRAZOLE IN BULK AND PHARMACEUTICAL DOSAGE FORM USING WOOL FAST BLUE
}

\section{M.M.V. Yoganda Swamy}

Lecturer in chemistry, K.V.R. College, Nandigama, Dr. A.J. Pratapareddy, HOD, Department of chemistry, K.V.R. College, Nandigama.

\section{ABSTRACT}

The new, selective and sensitive visible spectrophotometric method has been developed for the estimation of Esomeprazole in bulk and in pharmaceutical preparations. This method is based on the reaction with wool fast blue, in the presence of buffer at $\mathrm{P}^{\mathrm{H}} 1.5$ to form a colored species with a $\lambda_{\max } 590 \mathrm{~nm}$. Beer's law is obeyed in the concentration range of $50-250 \mu \mathrm{g} / \mathrm{ml}$ for both the methods. The method was extended to pharmaceutical formulations and there was no interference form in any common pharmaceutical excipients and diluents. The result of analysis has been validated statistically and by recovery studies.

Keywords: Spectrophotometric determination Wool fast blue, Esomeprazole.

Article Info: Received 02 June, 2018; Review Completed 10 July 2018; Accepted 12 July 2018; Available online 15 July 2018

\section{Cite this article as:}

Yoganda Swamy M.M.V., New spectrophotometric determination of esomeprazole in bulk and pharmaceutical dosage form using wool fast blue, Journal of Drug Delivery and Therapeutics. 2018; 8(4):320-322 DOI: http://dx.doi.org/10.22270/jddt.v8i4.1802

*Address for Correspondence:

M.M.V. Yoganda Swamy, Lecturer in chemistry, K.V.R. College, Nandigama, Dr. A.J. Pratapareddy, HOD, Department of chemistry, K.V.R. College, Nandigama.

\section{INTRODUCTION}

Esomeprazole magnesium is a bis(5methoxy-2-[(S)-[(4methoxy-3, 5-dimethyl-2-pyridinyl) methyl]sulfinyl]1H-benzimidazole-1yl) magnesium trihydrate. Esomeprazole is the S-isomer of omeprazole, which is a mixture of the S- and R- isomers. The magnesium salt is a white to slightly colored crystalline powder. It contains 3 moles of water of solvation and is slightly soluble in water. The stability of esomeprazole magnesium is a function of $\mathrm{pH}$; it rapidly degrades in acidic media, but it has acceptable stability under alkaline conditions. At $\mathrm{pH}$ 6.8 (buffer), the half-life of the magnesium salt is about 19 hours at $25^{\circ} \mathrm{C}$ and about 8 hours at $37^{\circ} \mathrm{C}$. Its molecular formula is $\left(\mathrm{C}_{17} \mathrm{H}_{18} \mathrm{~N}_{3} \mathrm{O}_{3} \mathrm{~S}\right)_{2 \mathrm{MgX} .3 \mathrm{H} 2 \mathrm{O}}$ with molecular weight of 767.2 as a trihydrate and 713.1 on an anhydrous basis ${ }^{1,2}$.
The methods is based on the reaction of esomeprazole magnesium drug as a secondary amine with wool fast blue, the formed complex extracted into chloroform at $\mathrm{pH}$ 1.5. The chloroform extractable layer is used to determine the esomeprazole magnesium spectrophotometrically ${ }^{3}$.

The structure of esomeprazole magnesium is shown in below.<smiles>COc1ccc2[nH]c(SCc3ncc(C)c(OC)c3C)nc2c1</smiles>

Esomeprazole magnesium 


\section{Experiment:}

All spectral measurements were made on MAPADA double beam UV-Visible 1600 spectrophotometer \& on an ELICO SL 171 MINI SPEC Spectrophotometer. An ELICO LI-120 Digital $\mathrm{pH}$ meter was also used for $\mathrm{pH}$ measurements.

\section{METHOD $^{4-9}$ :}

The method is based on the reaction of each drug having secondary or tertiary or primary amino (aliphatic) group with wool fast blue, the formed complex extracted into chloroform at $\mathrm{pH}$ 1.5. The absorbance of ion pair complex form in extractable chloroform layer is measured at the wavelength of maximum absorbance for each drug against the reagent blank and the amount of drug is determined from the calibration curve made between the absorbance and the amount of drug.

\section{Spectrum of Esomeprazole treated with wool fast blue:}

The wavelength of maximum absorbance of the Esomeprazole drug treated with wool fast blue solution is ascertained by the following procedure.

Into a $10 \mathrm{ml}$ volumetric flasks, the standard drug solution $(1.0 \mathrm{mg} / \mathrm{ml})$ in chloroform were transferred and diluted with same so as to obtain $100 \mu \mathrm{g} / \mathrm{ml}$ of Esomeprazole. $0.5 \mathrm{ml}$ of Esomeprazole solution is transferred into a separating funnel. This solution $0.5 \mathrm{ml}$ of wool fast blue reagent $2 \mathrm{ml}$ buffer solution are added. Reaction mixture was shaken gently for $5 \mathrm{~min}$ and allowed to stand for $5 \mathrm{~min}$ so as to separate aqueous and chloroform layer. The chloroform layer is separated out and absorbance is measured in the wavelength range of 450 to $650 \mathrm{~nm}$, against the reagent blank.

The spectrum is given in below.

\section{Spectrum of Esomeprazole magnesium}

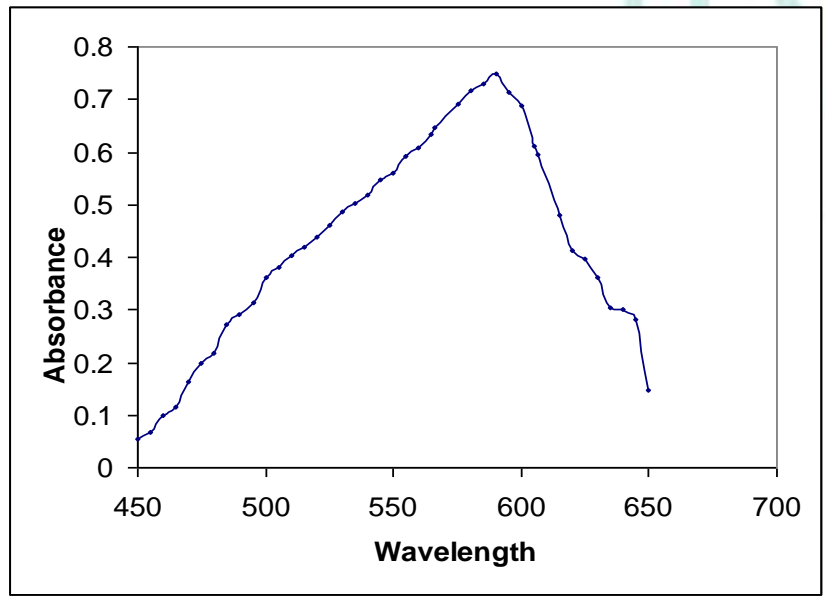

Spectrum of Esomeprazole magnesium

\section{Assay Procedure:}

Various aliquots of the standard Esomeprazole solution ranging from $0.5-2.5 \mathrm{ml}$ are transferred into a series of separating funnel. To each flask, $1.5 \mathrm{ml}$ of wool fast blue solution, $2.0 \mathrm{ml}$ of buffer solution and $5 \mathrm{ml}$ of chloroform are added. Reaction mixture in each funnel is shaken gently for $5 \mathrm{~min}$ and allowed to stand for $5 \mathrm{~min}$ so as to separate aqueous and chloroform layer. The chloroform layer is separated out and absorbance is measured at $590 \mathrm{~nm}$, against the reagent blank prepared in similar manner omitting drug solution. Calibration graph is obtained by plotting absorbance values against the concentration of Esomeprazole solution. The calibration curve is found to be linear over a concentration range of $50-250 \mu \mathrm{g} / \mathrm{ml}$ of Esomeprazole. The amount of Esomeprazole present in the sample is estimated from the calibration graph. The results are presented in the next page.

\section{Calibration curve of Esomeprazole magnesium}

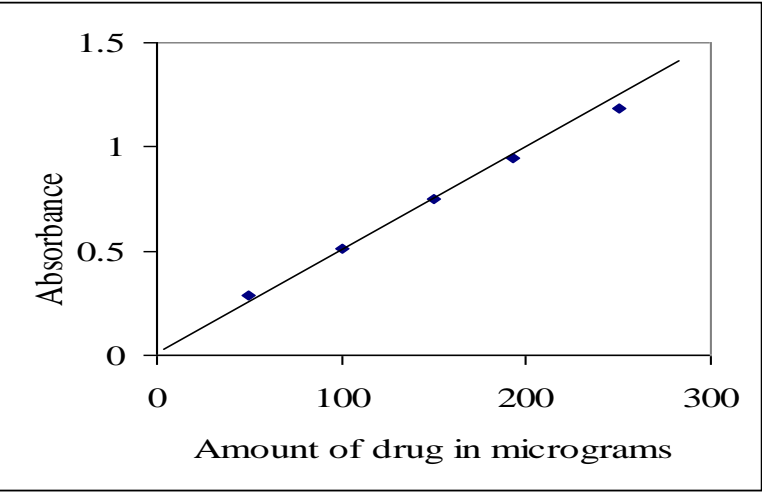

Calibration curve of Esomeprazole magnesium

\section{Pharmaceutical formulation of Esomeprazole:}

For analysis of tablet formulation, twenty tablets of Esomeprazole are weighed accurately and finely powdered. An accurately weighed portion of powdered sample, equivalent to $50 \mathrm{mg}$ of Esomeprazole was taken in a $50 \mathrm{ml}$ volumetric flask containing $25 \mathrm{ml}$ of chloroform, sonicated for 20 minutes.

The resultant solution is filtered through Whatmann filter paper No. 41 into another $50 \mathrm{ml}$ volumetric flask. The filter paper was washed several times with chloroform. The washings were added to the filtrate and the final volume was made up to the mark with methanol. Further sample solution is diluted and treated as per the procedure of the calibration curve. Amount of the drug present in sample was computed from respective calibration curve. The results are presented in following table. 
Table 1: Assay of Esomeprazole magnesium

\begin{tabular}{|c|c|c|c|c|c|}
\hline S.No & $\begin{array}{l}\text { Sample } \\
\text { (mg) }\end{array}$ & $\begin{array}{c}{ }^{*} \text { Amount Found(mg) } \\
\pm \text { S.D }\end{array}$ & $\begin{array}{c}\% \text { of } \\
\text { Label claim }\end{array}$ & ${ }^{*} \mathbf{C} . \mathbf{V}$ & $* \mathbf{t}_{\mathrm{cal}}$ \\
\hline 1 & 40 & $39.98 \pm 0.28$ & 99.95 & 0.7161 & 0.1562 \\
\hline 2 & 40 & $39.96 \pm 0.48$ & 99.90 & 1.207 & 0.1853 \\
\hline 3 & 40 & $40.02 \pm 0.43$ & 100.05 & 1.0804 & 0.1034 \\
\hline 4 & 40 & $40.06 \pm 0.35$ & 100.15 & 0.8928 & 0.3575 \\
\hline
\end{tabular}

\section{RESULTS AND DISCUSSION}

In this method the Esomeprazole treated with wool fast blue dye at $1.5 \mathrm{pH}$. The resultant solution is extracted with chloroform. The ion pair complex is formed in extractable chloroform layer. The absorbance of the extractable ion pair complex is measured at $590 \mathrm{~nm}$ against the reagent blank (prepared in a similar manner devoid of drug solution).

The calibration curve (concentration Vs absorbance) is linear over the range of $50-250 \mu \mathrm{g} / \mathrm{ml}$ of Esomeprazole.

The values of standard deviation are low, indicates high accuracy and reproducibility of the method. The ' $t$ ' calculated values are compared well with the theoretical value of 2.78 thereby indicating that the precision of the method.

There is no effect of additives and excipients such as starch, calcium lactose and glucose in the concentrations of those present in general pharmaceutical preparations.

\section{REFERENCES}

1. Rahman Nafisur, Bano Zehra, Syed Najmul Hejazmi, Journal of the Chinese Chemical Society, 2008; 55(3):557-566.

2. K.C. Carlsson and JLE. Reubsaet, J. Pharm.Biomed. Anal., 2004; 34(2):415-423.

3. Maheshwari R., Dahima R. "Solid as solvent": novel spectrophotometric analytical technique for quantitative estimation of tinidazole in tablets using solids (eutectic liquid of phenol and lignocaine hydrochloride) as solubilizing agents (mixed solvency concept). Journal of Drug Delivery and Therapeutics, 2017; 7(3):127-130. doi:10.22270/jddt.v7i3.1437

4. Chung T.C., Tai C.T., Wu H.L., J. Chromatogr. A, 2006; 1119(1-2):294-298.
The proposed method is found to be simple, precise, accurate and time saving, reproducible and can be conveniently adopted for routine analysis of estimation of Esomeprazole in bulk drugs samples and pharmaceutical formulations as seen from the agreement of the amount of Esomeprazole in the present method and the labeled amount of the pharmaceutical preparation.

\section{CONCLUSION}

The proposed method is found to be simple, precise, accurate and time saving reproducible and can be conveniently adopted for routine analysis of estimation of esomeprazole magnesium in bulk drug samples and pharmaceuticals formulations.

\section{ACKNOLEDGEMENTS}

The author is thankful to K. V . R . College management committee for providing the laboratory facilities.

5. Nizami T., Shrivastava B., Sharma P., Darwhekar G., Sharma P Spectrophotometric and Reversed-Phase High-Performance Liquid Chromatographic methods for simultaneous determination of atorvastatin and pioglitazone in combined tablet dosage form. Journal of Drug Delivery and Therapeutics, 2017; 7(7):116-117. doi:10.22270/jddt.v7i7.1605

6. Ciavarella A.B., Gupta A, Sayeed VA, Khan MA, Faustino PJ, J. Pharm. Biomed. Anal., 2007; 43(5):1647-1653.

7. Ciavarella A.B., Gupta A, Sayeed VA, Khan MA, Faustino PJ, J. Pharm. Biomed. Anal., 2008; 46(1):181-186.

8. Vermeij T.A.C., Edelbroek P.M., J. Chromatogr. B, 2004; 810(2):297-303. 